\title{
Gender inequalities in health and health care services use in Catalonia (Spain)
}

\author{
Esteve Fernandez, Anna Schiaffino, Luis Rajmil, Xavier Badia, Andreu Segura
}

\begin{abstract}
Background and objectives-While socioeconomically derived differences in health and health services use have long been a subject of study, differences based on gender, considered as the explicative variable, have scarcely been quantified from population-based data. The aim of this investigation was to analyse inequalities in health and health care services utilisation between men and women in Catalonia (Spain).

Design, setting, participants, and measures-Data from the Catalan Health Interview Survey, a cross sectional survey conducted in 1994, were used. A total of 6604 women and 5641 men aged 15 years or over were included for analysis. Health related variables studied were self perceived health, restriction of activity (past two weeks), and presence of chronic conditions; health services use variables analysed were having visited a health professional (past two weeks), an optometrist (12 months), or a dentist (12 months); and hospitalisation (past 12 months). Age standardised proportions were computed according to gender, and prevalence odds ratios (OR) were derived from logistic regression equations.
\end{abstract}

Main results-Women more frequently rated their health as fair or poor than men $(29.8 \%$ \% $21.4 \%$; OR=1.22; 95\% CI: 1.10 , 1.34). More women than men reported having restricted activity days $(O R=1.86$; 95\% CI: $1.59,2.18$ ) and chronic conditions $(\mathrm{OR}=1.74 ; 95 \%$ CI: $1.60,1.89)$. The proportion of women visiting a health professional was slightly greater than that for men (OR=1.20; 95\% CI: $1.09,1.31)$, as was the proportion of women visiting an optometrist $(\mathrm{OR}=1.21 ; 95 \% \mathrm{CI}: 1.11,1.33)$, and a dentist (OR=1.43; 95\% CI: $1.31,1.55)$. The proportion of hospitalisation was lower in women $(6.6 \%)$ than in men $(7.7 \%$; OR=0.73; 95\% CI: $0.63,0.85)$. When health services use was analysed according to self perceived health, women declaring good health reported a greater probability of consulting a health professional $(\mathrm{OR}=1.35$; 95\% CI: $1.20,1.52)$. There were no differences in respect to hospitalisation, visits to the optometrist and to the dentist.

Conclusions-These results indicate a pattern close to the inverse care law, as women, who express a lower level of health and thus would need more health care, are not, however, using health services more frequently than men.

(F Epidemiol Community Health 1999;53:218-222)

While gender differences in health, assessed in terms of mortality and morbidity, have been reported in most developed countries over recent decades, ${ }^{1-10}$ less attention has been paid to the pattern of health care services use. ${ }^{11-14}$

In Spain, as in most developed countries, the reduction of social inequalities in health and in access to health care is a matter of concern. Although social inequalities refer both to economic and gender differentials, the latter have received less attention. Crude data from Health Interview Surveys conducted in Barcelona $^{1516}$ and Spain ${ }^{17} 18$ indicated that women were more likely than men to declare a poor self perceived health status, that the average number of bed days per year was greater among women, while there were no differences between women and men in hospitalisation rates. Data from different European countries showed a similar pattern. ${ }^{19}$ Recent investigations, also based on data from the Spanish National Health Interview Survey, have demonstrated social inequalities in self perceived health, and in use and accessibility to health care services in Spain. ${ }^{20}{ }^{21}$ These and other studies, however, have analysed socioeconomic differences according to social class, level of education, and income, in men and women separately, or "adjusting for gender", ${ }^{22}$ without considering inequalities in health and health care services use "according to gender". Moreover, few studies have analysed gender differences in health services use while taking into account the need for care. Sex is generally treated in most medical and health services research as a potential confounder rather than an explicative variable. ${ }^{23}$

Our purpose in this study was to investigate gender-based inequalities in health and health care services utilisation, using data from the 1994 Catalan Health Interview Survey.

\section{Methods}

The 1994 Catalan Health Interview Survey was a cross sectional survey based on a representative sample of the noninstitutionalised population of Catalonia (an autonomous region in the north east of Spain). As well as sociodemographic data, the survey included self reported information on morbidity, health status, lifestyles, and use of health care services.

Fifteen thousand subjects were randomly selected using a multiple stage random sampling strategy. For each of the eight health regions of Catalonia, the first sampling stage 
Table 1 Distribution of 5641 men and 6604 women according to age, social class, marital status, and geographical area, Catalan Health Interview Survey, 1994

\begin{tabular}{|c|c|c|c|c|}
\hline & \multicolumn{2}{|l|}{ Men } & \multicolumn{2}{|c|}{ Women } \\
\hline & No & $(\%)$ & No & $(\%)$ \\
\hline Total & 5641 & $(46.1)^{\star}$ & 6604 & $(53.9)^{\star}$ \\
\hline \multicolumn{5}{|l|}{ Age (y) } \\
\hline $15-24$ & 1239 & $(20.0)$ & 1259 & $(19.1)$ \\
\hline $25-34$ & 880 & $(15.6)$ & 978 & $(14.8)$ \\
\hline $35-44$ & 894 & (15.8) & 1077 & $(16.3)$ \\
\hline $45-54$ & 832 & (14.8) & 1010 & $(15.3)$ \\
\hline $55-64$ & 856 & $(15.2)$ & 926 & $(14.0)$ \\
\hline $65-74$ & 635 & (11.3) & 831 & $(12.6)$ \\
\hline$\geqslant 75$ & 305 & $(5.4)$ & 574 & $(7.9)$ \\
\hline \multicolumn{5}{|l|}{ Social class } \\
\hline I & 352 & $(6.2)$ & 229 & (3.5) \\
\hline II & 843 & $(14.9)$ & 935 & $(14.2)$ \\
\hline III & 1108 & $(19.6)$ & 1164 & $(17.6)$ \\
\hline IV & 2938 & $(52.1)$ & 3252 & $(49.2)$ \\
\hline $\mathrm{V}$ & 33 & $(5.8)$ & 815 & $(12.3)$ \\
\hline Unknown & 71 & (1.3) & 209 & $(3.2)$ \\
\hline \multicolumn{5}{|l|}{ Marital status } \\
\hline Bachelor & 1891 & (33.5) & 1724 & $(26.1)$ \\
\hline Married & 3534 & $(62.7)$ & 3888 & $(59.0)$ \\
\hline Separate/divorced & 69 & $(1.2)$ & 190 & $(2.8)$ \\
\hline Widowed & 143 & $(2.5)$ & 792 & $(12.0)$ \\
\hline \multicolumn{5}{|l|}{ Area of residence } \\
\hline I & 358 & $(6.4)$ & 358 & $(5.4)$ \\
\hline II & 414 & $(7.3)$ & 429 & $(6.5)$ \\
\hline III & 109 & $(1.9)$ & 123 & $(1.9)$ \\
\hline IV & 465 & $(8.2)$ & 541 & $(8.2)$ \\
\hline $\mathrm{V}$ & 1042 & $(18.5)$ & 1204 & $(18.2)$ \\
\hline VI & 621 & $(11.0)$ & 737 & $(11.2)$ \\
\hline VII & 1119 & $(19.8)$ & 1300 & $(19.7)$ \\
\hline VIII & 1514 & $(26.8)$ & 1911 & $(28.9)$ \\
\hline
\end{tabular}

* Percentage among the total sample (row percentage).

(of eight strata) consisted of selecting municipalities (or municipal districts in the case of the Barcelona health region) according to their population size. In each of these strata, cluster random sampling was used to select subjects, by using proportional probabilities according to the weight of the municipality (or district). Trained interviewers administered the questionnaires from January to December 1994 to avoid potential seasonality. Only $5.4 \%$ of subjects were substituted because of refusal or absence of those initially selected. Two different questionnaires were used: one for subjects aged $\geqslant 15$ and a reduced form (excluding self perceived health and other lifestyle variables) for those aged $<15$ or not able to answer by

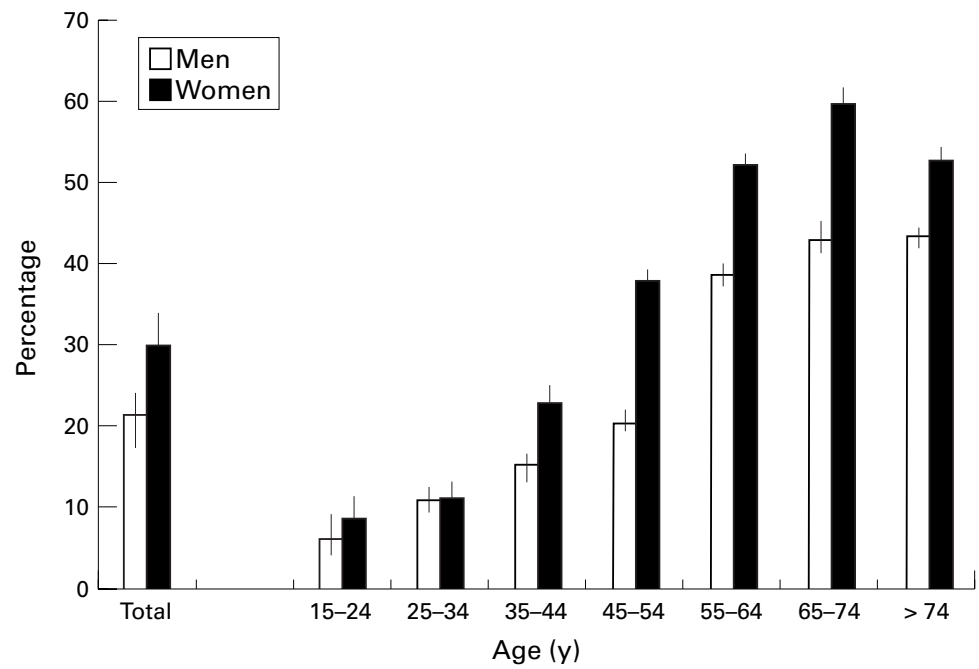

Figure 1 Age standardised and age specific proportions (and 95\% confidence intervals) of men and women with fair or poor self perceived health, Catalan Health Interview Survey, 1994.
Table 2 Age standardised proportions and prevalence odds ratios (and 95\% confidence intervals) of fair or poor self perceived health, presence of restricted activity in past two weeks, and presence of chronic conditions, according to gender, Catalan Health Interview Survey, 1994

\begin{tabular}{lcl}
\hline \multicolumn{3}{c}{ Proportion $^{*}$ OR $(95 \% \mathrm{CI})+$} \\
\hline Fair or poor self perceived health & \\
Men & 21.4 & $1 \neq$ \\
Women & 29.8 & $1.22(1.10,1.34)$ \\
Presence of restricted activity (past two weeks) \\
Men & 8.9 & $1 \neq$ \\
Women & 13.4 & $1.86(1.59,2.18)$ \\
Presence of chronic conditions & 54.4 & $1 \neq$ \\
Men & 64.2 & $1.74(1.60,1.89)$ \\
Women &
\end{tabular}

* Age-standardised by the direct method.

† Odds ratio and $95 \%$ confidence intervals, adjusted for age, social class, area of residence, and number of chronic conditions (when required)

$\ddagger$ Reference category.

themselves (direct and indirect questionnaire, respectively). ${ }^{24}$ For the present analysis, only direct responses ( $n=12$ 245) were analysed.

HEALTH RELATED VARIABLES

Ratings of self perceived health were obtained using the question "In general, how would you say your health is?", with response options of 'Excellent, very good, good, fair, or poor'. For analysis purposes, answers were grouped into two categories: "good health" (excellent, very good and good) and "poor health" (fair and poor). Data on the degree of restricted activity (no/yes) over the two weeks before the interview were obtained by pooling responses to three questions: "from ( 15 days ago) to yesterday, have you had to stay in bed, for at least half a day, including hospitalisation, because of your health?", "apart from days you have spent in hospital or in bed at home, over the past 15 days, have you not gone to your work or school, or have you not performed your work around the house because of your health?", and "moreover, have you restricted or decreased your usual activities (for example, walking, shopping, jogging, etc) over the past 15 days because of your health?". The presence of chronic conditions was elicited using a list of 16 common chronic conditions. A dichotomous variable (absence/presence of chronic conditions) was created for the analysis when considered as dependent variable, and an ordinal variable (number of chronic conditions: 0 , $1,2, \geqslant 3$ ) was used when included for adjustment.

USE OF HEALTH CARE SERVICES VARIABLES

Consultation with a health professional over the two weeks before the interview (no/yes) included either in-person visits or telephone consultations with a primary health care physician, specialist doctor (excluding gynaecological and obstetric visits, and visits to the dentist and optometrist), nurse, or other health professionals. Consultation with an optometrist or a dentist during the year before the interview was specifically elicited, as was hospitalisation in the year before the interview, for a minimum stay of at least one night ("Have you been hospitalised during the last 12 months?" (no/yes)). The reason for hospitalisa- 
Table 3 Age standardised proportions and prevalence odds ratios (and 95\% confidence intervals) of having visited a health professional in the past two weeks, an optometrist in the past year, a dentist in the past year, and having been hospitalised in the past year according to gender, Catalan Health Interview Survey, 1994

\begin{tabular}{|c|c|c|}
\hline & Proportion* & OR $(95 \% C I)+$ \\
\hline \multicolumn{3}{|c|}{ Visit to a health professional (past two weeks) } \\
\hline Men & 18.1 & $1 \neq$ \\
\hline Women & 24.9 & $1.20(1.09,1.31)$ \\
\hline \multicolumn{3}{|c|}{ Visit to an optometrist (past year) } \\
\hline Men & 20.6 & $1 \neq$ \\
\hline Women & 24.2 & $1.21(1.11,1.33)$ \\
\hline \multicolumn{3}{|c|}{ Visit to a dentist (past year) } \\
\hline Men & 23.8 & $1 \neq$ \\
\hline Women & 30.5 & $1.43(1.31,1.55)$ \\
\hline \multicolumn{3}{|c|}{ Hospitalisation (past year) } \\
\hline Men & 7.7 & $1 \neq$ \\
\hline Women & 6.6 & $0.73(0.63,0.85)$ \\
\hline
\end{tabular}

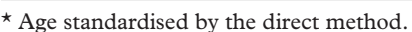

† Odds ratio and $95 \%$ confidence intervals, adjusted for age, social class, area of residence, number of chronic conditions, and type of health insurance.

$\ddagger$ Reference category.

tion was elicited for the most recent episode. Hospitalisations for pregnancy and delivering were excluded in the analysis (WONCA codes: 633-, 640-, 6466, 642-, 636-, 634, 648-, $650-) .^{25}$

DATA ANALYSIS AND CONTROL OF CONFOUNDING As age is a major determinant of health and health services use, direct standardisation based on the 1991 Catalan census in decades was used to obtain age adjusted proportions of men and women for each of the dependent variables. ${ }^{26}$ Prevalence odds ratios (OR) and corresponding 95\% confidence intervals (CI) were computed by means of logistic regression to estimate the association between gender and health and health care services use variables. ${ }^{27}$ The regression equations included terms for age (in decennia), social class (adapted from the British Registrar General, ${ }^{28}$ based on the occupation of the subject, both for men and women, or of the household's head for homemaker women and students,), area of residence (the eight health regions), and number of chronic conditions ( 0 , $1,2, \geqslant 3$ ) for the health related variables; and, in addition, self perceived health (good/poor) and

Table 4 Age standardised proportions and prevalence odds ratios (and 95\% confidence intervals) of having visited a health professional in the past two weeks, an optometrist in the past year, a dentist in the past year, and having been hospitalised in the past year according to gender and self perceived health status, Catalan Health Interview Survey, 1994

\begin{tabular}{|c|c|c|c|c|}
\hline & \multicolumn{4}{|c|}{ Self perceived health } \\
\hline & \multicolumn{2}{|c|}{ Fair or poor } & \multicolumn{2}{|c|}{ Excellent, very good or good } \\
\hline & $\%$ * & OR $(95 \% C I)+$ & $\% *$ & OR $(95 \% C I)+$ \\
\hline \multicolumn{5}{|c|}{ Visit to a health professional (past two weeks) } \\
\hline Men & 31.7 & $1 \neq$ & 14.4 & $1 \neq$ \\
\hline Women & 36.9 & $1.06(0.91,1.24)$ & 20.0 & $1.35(1.20,1.52)$ \\
\hline \multicolumn{5}{|c|}{ Visit to an optometrist (past year) } \\
\hline Men & 21.9 & $1 \ddagger$ & 19.7 & $1 \neq$ \\
\hline Women & 27.9 & $1.16(0.98,1.37)$ & 22.1 & $1.09(0.98,1.22)$ \\
\hline \multicolumn{5}{|c|}{ Visit to a dentist (past year) } \\
\hline Men & 24.4 & $1 \neq$ & 23.7 & $1 \neq$ \\
\hline Women & 28.9 & $1.21(1.02,1.45)$ & 30.6 & $1.41(1.28,1.55)$ \\
\hline \multicolumn{5}{|c|}{ Hospitalisation (past year) } \\
\hline Men & 14.4 & $1 \ddagger$ & 5.7 & $1 \neq$ \\
\hline Women & 11.6 & $0.77(0.63,0.94)$ & 4.7 & $0.66(0.54,0.82)$ \\
\hline
\end{tabular}

* Age standardised by the direct method.

† Odds ratio and $95 \%$ confidence intervals, adjusted for age, social class, area of residence, number of chronic conditions, and type of health insurance.

$\ddagger$ Reference category.
KEY POINTS

- Women declare a lower level of health than men (poor self perceived health, more restricted activity days, more chronic conditions).

- The proportion of hospitalisation is lower in women than in men (even after excluding pregnancy and delivering related hospitalisations).

- Research in inequalities in health and in health care services use might include analyses according to gender and to the need of care.

type of health insurance (only public/public plus private) for the health services utilisation variables. In all analyses, sampling weights derived from the complex sample design of the Catalan Health Interview Survey were included to maintain the sample's representativity. ${ }^{24}$

\section{Results}

As shown in table 1, there were only slight differences in age, social class, and marital status between the 5641 men and 6604 women interviewed, and geographical distribution was similar.

Women rated their health as fair or poor $(29.8 \%)$ more frequently than men $(21.4 \%)$. The proportion of women was greater in all age groups, and the difference increased with age (fig 1). When age, social class, geographical area, and number of chronic conditions were taken into account the differences persisted (OR of fair or poor health for women $=1.22$; 95\% CI: $1.10,1.34$ ) (table 2). More women $(13.4 \%)$ than men $(8.9 \%)$ declared having had a restricted activity day in the two weeks before the interview, corresponding to an $\mathrm{OR}=1.86$ (95\% CI: 1.59, 2.18). The presence of any chronic condition was more frequent among women, as compared with men $(\mathrm{OR}=1.74$; $95 \%$ CI: $1.60,1.89)$. The proportion of men and women with restricted activity and chronic conditions increased with age, and gender differences were of similar magnitude in all age groups (data not shown).

Table 3 shows the distribution of men and women according to health care services utilisation. A slightly greater proportion of women consulted a health professional in the two weeks before the interview, corresponding to an OR of 1.20 (95\% CI: $1.09,1.31)$. Women were more likely to have visited an optometrist $(\mathrm{OR}=1.24 ; 95 \% \mathrm{CI}: 1.11,1.33)$ or a dentist $(\mathrm{OR}=1.43 ; 95 \% \mathrm{CI}: 1.31,1.55)$ during the year before interview. The proportion of hospitalisation was lower in women $(6.6 \%)$ than in men $(7.7 \%)$. When age and other adjustment variables were included in the regression equations (table 3 ) an inverse association was found (OR=0.73; 95\% CI: 0.63, 0.85).

A stratified analysis was conducted to determine whether the pattern of health service utilisation was different according to need of care, measured as self perceived health. As shown in table 4 , there were no apparent differences according to need of care in respect to 
hospitalisation, visits to the optometrist and to the dentist. Women declaring good health reported a greater probability of consulting a health professional $(\mathrm{OR}=1.35 ; 95 \% \mathrm{CI}: 1.20$, 1.52) as compared with men declaring their health as good.

\section{Discussion}

The data presented here show that, in general, women have a worse health status (measured in terms of self perceived health, restriction of activity and presence of chronic conditions) than men. Nevertheless, women make only a slight greater use of health care facilities, mainly outpatient visits, and are less likely to be hospitalised than men. This is more evident when the need for health care, measured in terms of self perceived health, is taken into account.

Crude data from previous Health Interview Surveys in Spain revealed gender-based differences in self perceived health. In Barcelona, ${ }^{16}$ the proportion of women and men who declared their health as fair, poor or very poor was $26.8 \%$ and $18.2 \%$ respectively in 1992 . In the 1993 Spanish National Health Interview Survey, ${ }^{18}$ these proportions were $36 \%$ and $27 \%$ for women and men respectively. Likewise, the proportions of women $(28.9 \%)$ and men $(21.4 \%)$ who expressed fair or poor self perceived health in Catalonia were similar to proportions found in surveys carried out in other European countries: between $23-26 \%$ in women and $18-22 \%$ in men. ${ }^{19}$ Women were also more likely to have had a restricted activity day in the two weeks before the interview, and to have a chronic condition. These associations persisted after controlling for age, social class and, in the case of self perceived health and restriction of activity, for comorbidity, measured as the number of chronic conditions declared. We were not able to take into account, however, the potential effect of family roles and family structure, or contribution to housework. ${ }^{3929}$ Rohlfs et $a l^{30}$ have recently shown, in an analysis of data obtained from 1194 women interviewed in the 1992 Barcelona Health Interview Survey, that homemaker women declared worse self perceived health than women in paid employment $(\mathrm{OR}=1.7$, 95\% CI: $1.2,2.4$ ), whereas no clear pattern of association was evident by social class.

With respect to visits to health professionals over the two weeks before the interview, figures for women and men were similar to those derived from the 1992 Barcelona Health Interview Survey and the 1993 Spanish National Health Interview Survey. Whereas women tended to use more outpatient medical services, the data showed that women were less often hospitalised than men. This is confirmed in the stratified analysis according to self perceived health status. Women, whose worse overall health status could be interpreted as reflecting a greater need for health care, actually have a slightly higher level of medical visits but a low rate of hospitalisation, even after adjusting for type of health insurance and number of chronic conditions. This inverse pattern of health care services use according to need is close to the inverse care law. ${ }^{31}$

It has been proposed that the higher overall morbidity among women might be accounted for by gynaecological and obstetrical causes, in contrast with the frequently alleged higher rates of unspecified psychosomatic symptoms among women. ${ }^{13}$ In this study we used the number of chronic conditions to adjust for comorbidity, although a more precise adjustment should consider the type and nature of these conditions.

Some limitations and strengths of the study deserve consideration. Selection bias is unlikely to play an important part, as the sample was large, and representative of the Catalan population $(0.25 \%$ of the approximately 6 million inhabitants). Compliance was almost total $(94.6 \%)$, and proxy interviews, from subjects under 14 years of age or subjects aged 15 or over but unable to answer for themselves, were not included in the present analysis to avoid the possibility of differential recall. Moreover, information on self perceived health was not elicited in the proxy questionnaire. ${ }^{24}$

Some concern would stem from the possibility of unreliable recall, as all data were self reported. Self perceived health status has been extensively used in Health Interview Surveys as well as in other types of observational studies, and is positively associated with need for health care, morbidity and mortality. ${ }^{32-34}$ The reporting of restriction of activity and chronic conditions or diseases has been found to be reliable, ${ }^{35-37}$ as has self reported hospitalisation and ambulatory physician visits over a two week period. ${ }^{38-40}$ Although for hospitalisation the recall period was 12 months, for most people hospitalisation is a major life event that is likely to be accurately recalled. Medical visits in a longer recall period (12 months) are, however, less accurate. ${ }^{38} 40$ Differences in recall of health state and health care services use according to sex seem unlikely, although some authors have argued that women may be more sensitised to suffering and recall minor illnesses and symptoms more frequently. ${ }^{1341}$ One explanation often cited for the apparently higher morbidity among women is that they are more sensitive than men to bodily discomfort, and are more willing to report or to express symptoms of distress and ill health. ${ }^{8}$ Some studies also indicate that women prefer to receive care from female doctors as they are more sensitised to female problems than male doctors. ${ }^{42}$ A similar phenomenon would be possible in interviews in relation to the sex of the interviewer: female interviewers presumably may elicit a greater response from female respondents, which might contribute to sex differences in morbidity.

With reference to confounding, regression equations included major potential confounders, including age, social class, area of residence, type of health care insurance (which may determine the accessibility to health care services), self perceived health and number of chronic conditions (which may account for the level of need for health care). Further allowance for other health related variables (restric- 
tion of activity or having had a bed-day in the previous two weeks) did not modify the pattern of association. Previous reports suggested that there is an underlying health disadvantage for men once confounding factors are controlled. ${ }^{83}$ In this study, adjustment for covariates produced some attenuation in the magnitude of the estimates but the associations observed between female sex and poor health, presence of chronic conditions, and presence of restricted activity remained, and were unlikely to be because of chance. Sayer and Britt, ${ }^{8}$ who studied gender differentials in doctor-patient encounters in general practice, included other potential confounding variables such as the sex of the attending physician and the patient's reasons for encounter.

This study, based on a Southern European population where universal coverage and access to health care services are guaranteed by a national health service, shows that women declare a worse health status and thus have a greater need for health care, but that they none the less report only a slightly higher level of medical consultation and lower levels of hospitalisation than men. This pattern of unmet need for health services among women should be further investigated in this population. Whether these findings would be reproducible in other countries, and their relation with the type of health care provision (public and/or private) are also concerns for future research. Research in inequalities in health and in health care services use might include analyses according to sex and to the need of care to further elucidate the complex gender differentials and their implications in the design and implementation of health policies. ${ }^{142344}$

This investigation was partially supported by a contract between the Catalan Health Service and the Institut de Salut Pública de Catalunya (ISP\#96/00663). The opinions presented are solely the responsibility of the authors. They are grateful to Ms Eulàlia the responsibility of the authors. They are grateful to Ms Eulàlia of the "Biblioteca Universitària de Bellvitge" and the "Biblioteca del Departament de Sanitat" for their help. Preliminary teca del Departament de Sanitat" for their help. Preliminary
results were presented at the XIV Scientific Meeting of the results were presented at the XIV Scientific Meeting of the
Spanish Society of Epidemiology, October 22-25, 1996, Zaragoza, Spain (Gac Sanit 1996;10 (suppl 2):84).

1 Verbrugge LM. Sex differentials in health. Public Health Rep 1982;97:417-37.

2 Wingard DL. The sex differential in morbidity, mortality and lifestyle. Annu Rev Public Health 1984;5:433-58.

3 Verbrugge LM. Gender and health: an update on hypotheses and evidence. $\mathcal{F}$ Health Soc Behav 1985;26:156-82.

4 Havvio-Mannila E. Inequalities in health and gender. Soc Sci Med 1986;22:141-9.

5 Arber S. Gender and class inequalities in health: understanding the differentials. In: Fox J, ed. Health inequalities in European countries. Aldershot: Gower Company, 1989:25079.

6 Wingard DL, Cohn BA, Kaplan GA, et al. Sex differentials in morbidity and mortality risks examined by age and cause in the same cohort. Am f Epidemiol 1989;130:601-10.

7 Ross CE, Bird CE. Sex stratification and health lifestyle: consequences for men's and women's perceived health. $\mathscr{f}$ consequences for men's and wom
Health Soc Behav 1994;35:161-78.

8 Sayer GP, Britt H. Sex differences in morbidity: a case of discrimination in general practice. Soc Sci Med 1996;42: 257-64.

9 Macran S, Clarke L, Joshi H. Women's health: dimensions and differentials. Soc Sci Med 1996;42:1203-16.

10 Macintyre S, Hunt K, Sweeting H. Gender differences in health: are things really as simple as they seem? Soc Sci Med 1996;42:617-24.

11 Mechanic D. Sex, illness, illness behavior and the use of health services. Soc Sci Med 1978;12:207-12.
12 Hibbard JH, Pope CR. Gender roles, illness orientation and use of medical services. Soc Sci Med 1983;17:129-37.

13 Gijsbers van Wijk CM, Kolk AM, van den Bosch WJ, et al. Male and female morbidity in general practice: the nature of sex differences. Soc Sci Med 1992;35:665-78.

14 Gijsbers van Wijk CM, van Vliet KP, Kolk AM. Gender perspectives and quality of care: towards appropriate and adequate health care for women. Soc Sci Med 1996;43:70720.

15 Alonso J, Antó JM. Desigualtats de salut a Barcelona. Gac Sanit 1988;2:4-12.

16 Borrell C, Passarín I, Plasència A. Enquesta de Salut de Barcelona 1992-93. Estadístiques de Salut No. 23. Barcelona: Ajuntament de Barcelona, 1995.

17 Ministerio de Sanidad y Consumo. Encuesta Nacional de Salud 1987. Madrid: Ministerio de Sanidad y Consumo, 1989.

18 Ministerio de Sanidad y Consumo. Encuesta Nacional de Salud 1993. Madrid: Ministerio de Sanidad y Consumo, 1995.

19 Netherlands Central Bureau of Statistics \& Erasmus University. International variation in socio-economic inequalities in self-reported health. Voorburg: Netherlands Central Bureau of Statistics, 1992.

20 Fernández de la Hoz K, Leon DA. Self-perceived health status and inequalities in use of health services in Spain. Int $\mathcal{F}$ Epidemiol 1996;25:593-603.

21 Regidor E, de Mateo S, Gutierrez-Fisac JL, et al. Diferencias socioeconómicas en la utilización y accesibilidad de los ervicios sanitarios en España. Med Clin (Barc) 1996;107: $285-8$.

22 Chapman Walsh D, Sorensen G, Leonard L. Gender, health, and cigarette smoking. In: Amick III BC, Levine S, Tarlov AR, et al, eds. Society and health. Oxford: Oxford University Press, 1995.

23 Ruiz MT, Verbrugge LM. A two way view of gender bias in medicine. F Epidemiol Community Health 1997;51:106-9.

24 Servei Català de la Salut. Document Tècnic. Enquesta de Salut de Catalunya (ESCA). Barcelona: Servei Català de la Salut, Departament de Sanitat i Seguretat Social, Generalitat de Catalunya, 1996.

25 WONCA. Classificacions de la WONCA per a l'atenció primària [The international classification of health probems in primary care (ICHPPC-2-defined)]. Barcelona: Masson, SA; 1986

26 Rué M, Borrell C. Los métodos de estandarización de tasas. Revisiones Salud Publica 1993;3:263-95.

27 Kleinbaum DG, Kupper LL, Morgenstern H. Epidemiologic research. Principles and quantitative methods. Belmont, CA: Lifetime Learning Publications, 1982.

28 Domingo A, Marcos J. Propuesta de un indicador de "clase social” basado en la ocupación. Gac Sanit 1989;3:320-6.

29 Verbrugge LM. Multiple roles and physical health of women and men. F Health Soc Behav 1983;24:16-30.

30 Rohlfs I, de Andrés J, Artazcoz L, et al. Influencia del trabajo remunerado en el estado de salud percibido de las mujeres. Med Clin (Barc) 1997;108:566-71.

31 Hart JT. The inverse care law. Lancet 1971;i:405-12.

32 Goldstein MS, Siegel JM, Boyer R. Predicting changes in perceived health status. Am F Public Health 1984;74:611 4

33 Idler EL, Kasl SV, Lemke JH. Self-evaluated health and mortality among the elderly in New Haven, Connecticut, and Iowa and Washington counties, Iowa, 1982-1986. Am 7 Epidemiol 1990;131:91-103.

34 Maddox GL, Douglass EB. Self-assessment of health: a longitudinal study of elderly subjects. F Health Soc Behav 1973;14:87-93.

35 Harlow SD, Linet MS. Agreement between questionnaire data and medical records. The evidence for accuracy of recall. Am ₹ Epidemiol 1989;129:233-48.

36 Bush TL, Miller SR, Golden AL, et al. Self-report and medical record report agreement of selected medical conditions in the elderly. Am f Public Health 1989;79:1554-

37 Mackenbach JP, Looman CW, van der Meer JB. Diffences in the misreporting of chronic conditions, by level of education: the effect on inequalities in prevalence rates. $\mathrm{Am}$ f Public Health 1996;86:706-11.

38 Cleary PD, Jette AM. The validity of self-reported physician utilization measures. Med Care 1984;22:796-803.

39 Norrish A, North D, Kirkman P, et al. Validity of self-reported hospital admission in a prospective study. $\mathrm{Am}$ f Epidemiol 1994;140:938-42.

40 Roberts RO, Bergstralh E, Schmidt L, et al. Comparison of self-reported and medical record health care utilization measures. F Clin Epidemiol 1996;49:989-95.

41 Verbrugge LM. The twain meet: empirical explanations of sex differences in health and mortality. F Health Soc Behav 1989;30:282-304

42 Bensing JM, Brink Muinen A, Baker DH. Gender differences in practice style: a ducth study of general pracitioners. Med Care 1993;31:219-29.

43 Bird CE, Fremont AM. Gender, time use, and health. $\mathcal{F}$ Health Soc Behav 1991;32:114-29.

44 Regidor E. Investigación y acción sobre las desigualdades en salud. Med Clin (Barc) 1997;108:784-90. 